\title{
Condition Monitoring of Variable Speed Worm Gearbox Lubricated With Different Viscosity Oils
}

\author{
Maznan Ismon ${ }^{1,2, a}$, Izzuddin Zaman ${ }^{1,2, b}$ and Mohd Imran Ghazali ${ }^{1}$ \\ ${ }^{1}$ Faculty of Mechanical and Manufacturing Engineering, ${ }^{2}$ Structural Integrity and Monitoring \\ Research Group, Universiti Tun Hussein Onn Malaysia, 86400 Batu Pahat, Johor, Malaysia \\ amaznan@uthm.edu.my, bizzuddin@uthm.edu.my
}

Keywords: Condition monitoring, worm gear, vibration, thermograph

\begin{abstract}
Over the years, condition monitoring of gear transmission systems have captured significant worldwide attention from both industries and academia. This is in light of the fact that an effective condition monitoring techniques will unquestionably extend the life span of the rotating equipment. In this research, both the vibration and temperature monitoring techniques were utilized to characterize the vibration behavior of worm gear as function of gear lubricant's viscosity. Three different types of lubricant's viscosity; VG100, VG460 and VG680 were used in the study to serve the sliding friction of worm gears. The predetermined speeds of electric motor at 900, 1150 and $1400 \mathrm{rpm}$ were introduced to the gearbox prior to the measurement of vibration signal and temperature profile. The results revealed that a lubricant with higher viscosity contributes to less vibration amplitude. At $1150 \mathrm{rpm}$, it was recorded that the vibration amplitudes are higher compare to the other motor speeds, for all lubricant's types. In this case, VG100 showed the highest vibration amplitude followed by VG460 and VG680. This result was corroborated well with the obtained temperature profiles which are $35.0^{\circ} \mathrm{C}, 35.7^{\circ} \mathrm{C}$ and $39.3^{\circ} \mathrm{C}$ for the respective VG100, VG460 and VG680. Thus, concludes the correlation between the lubrication's viscosity, vibration level, temperature profile and worm gear speed.
\end{abstract}

\section{Introduction}

Industrial operations are much depending on the rotating equipment to ensure continuous plant operation or production performance. One of the commonly used rotating equipments at industrial worldwide is gearboxes, which have been known to play important role to the industrial performance [1,2]. Generally, the main internal components of the gearboxes are named shaft, gear, bearing and seal, yet gear and bearing remains the most components contribute to a major breakdown in rotating equipment.

This issue arisen due to gradual deterioration and wear of the gears and bearing that much related to the rotating equipment working within an excessive load condition, excessive vibration and lack performance of lubricants. In fact, some researches have been done as to develop the understanding and correlations of contaminated gear oil which generally will contribute to gears failure [3,4]. The latter, however, is considered to be a main factor for determining the performance of gears and bearing within the optimum operating condition. This is because any unscheduled breakdown would easily burst the maintenance cost, lapses in production schedule and even interfere with the human casualties. As to minimize the unscheduled breakdown, a proper maintenance practice and monitoring systems are required to detect faults in the early stages and provide alert notification to the operators [5]. This is where condition monitoring technique comes in handy where it could extend the life span of rotating equipment, reduce maintenance cost and avoid catastrophic failure to the gears and bearings $[6,7]$.

Vibration and temperature monitoring are the most regularly measured condition parameter in the rotating machinery, and it is continuously monitored in many important applications $[8,9]$. Although most industrial practice are still rely on the vibration spectral data analysis as a primary tools for assessing machine condition, both techniques have been established to have their unique advantages and disadvantages associated with the monitoring and fault diagnosis of machinery. When these techniques are conducted independently, only a portion of machine faults are typically 
diagnosed. However, practical experience has shown that by integrating these two techniques in a machine condition monitoring program will provides better and more reliable information, bringing significant cost benefits to industry. The commonly monitored vibration parameters are displacement, velocity, and acceleration. In spite of many books and references of vibration analysis to gear fault diagnosis are widely available, there is limited references and information pertaining to the monitoring of worm gearboxes performance.

Worm gearbox normally consists of one step speed reduction mechanism but capable for higher reduction ratio. It could be both low and high speed rotating parts internally as shown in Fig. 1. Since the vibration analysis could predict the gear failure effectively, the application need to be extend to the output shaft of worm gearboxes which typically has great speed reduction compared to the input shaft. Previous study by Elforjani et al. [7] showed that most of the gear failures are result of shaft bending and surface fatigue. In the study, the author and his co-workers also addressed the limitation of vibration analysis to low speed rotating machine of worm gear. Therefore, a further study still needs to be conducted to analyze the correlation between the worm gear speed, vibration, lubricant characteristic and temperature.

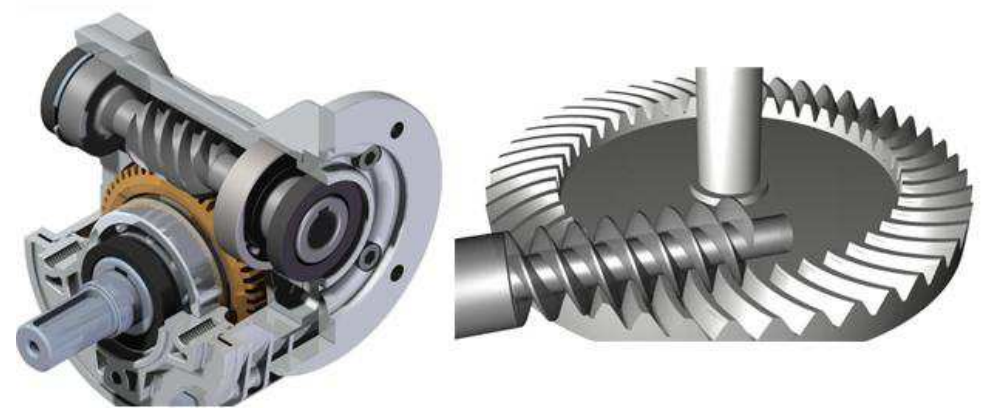

Fig. 1. Potential of plate's applications

In this research study, the worm gears vibration characteristics are determined with provided new oil as a baseline value. The study is extended to lubricant's temperature in order to seek correlations with mechanical vibration. The outcomes will reveal more understanding on the dependent and independent roles of vibration and temperature in predicting and diagnosing machine faults.

\section{Experimental Setup}

A specific designed test-rig, self fabricated as shown in Fig. 2 was employed in this investigation. It consists of a worm gearbox driven by a variable speed motor unit.

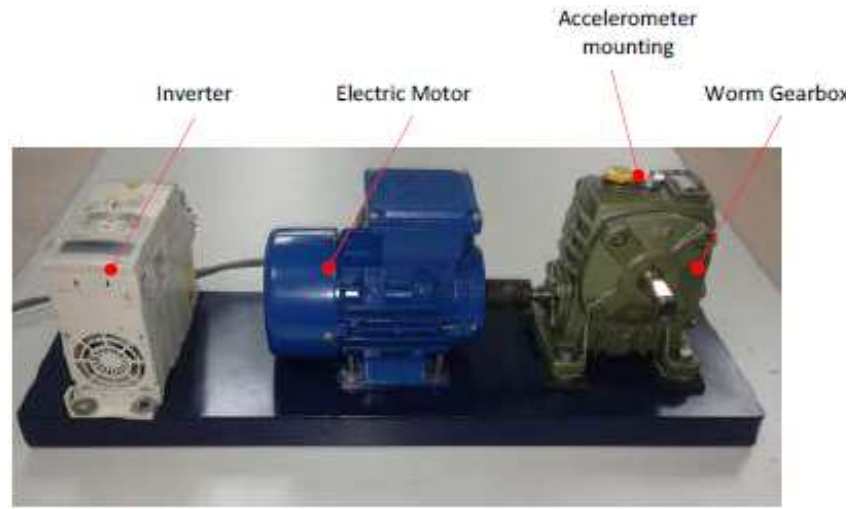

Fig. 2. Experimental rig for worm gears test
Table 1. Specification of gears and bearings for worm gear

\begin{tabular}{ll}
\hline Parameters & Specification \\
\hline Worm Gear & $\begin{array}{l}9 \text { Helical - Phosphorus } \\
\text { steel }\end{array}$ \\
$\begin{array}{l}\text { Bearing } \\
\text { Tooth wheel }\end{array}$ & $\begin{array}{l}\text { 60 Teeth Helical Concave } \\
\text { gear }\end{array}$ \\
$\begin{array}{l}\text { Tooth wheel } \\
\text { bearing }\end{array}$ & MXB 6204 6 - 8 ball \\
\hline
\end{tabular}


The worm gearbox used in this investigation is manufactured by JIE Asia Ltd, while the shaft is made of case-hardened EN34 steel and the teeth of the worm wheel is made of bronze alloy. The reduction ratio of the gearbox is 1:60 as the worm gear is located above the sixty teeth worm wheel. Table 1 tabulates the gears and bearing specification of the worm gearbox, while Table 2 tabulates the specification of the lubricant used in the experiment study.

Table 2: Specification of lubricants

\begin{tabular}{lccc}
\hline \multirow{2}{*}{ Parameters } & \multicolumn{3}{c}{ Gear Oil Specification } \\
\cline { 2 - 4 } & VG100 & VG460 & VG680 \\
\hline Type & Semi-synthetic & Semi-synthetic & Semi-synthetic \\
Viscosity at $40^{\circ} \mathrm{C}$ & $97 \mathrm{cSt}$ & $419 \mathrm{cSt}$ & $612 \mathrm{cSt}$ \\
Flash point & $207^{\circ} \mathrm{C}$ & $217^{\circ} \mathrm{C}$ & $221^{\circ} \mathrm{C}$ \\
\hline
\end{tabular}

\section{Results and Discussion}

Rotational speed. A theoretical gear mesh frequency (GMF) is calculated by using Eqs 1-3. Based on these equations, the rotational frequencies of the output and input rotor for the gearbox were obtained as indicated in Table 3.

$$
\begin{aligned}
& \text { Rotation Frequency }(\mathrm{Hz})=\mathrm{RPM} / 60 \\
& \text { Period }(\mathrm{s})=1 / \text { Rotation Frequency }(\mathrm{Hz}) \\
& \text { Gear Mesh Frequency }(\mathrm{GMF})=\text { No. of Teeth } \times \text { Rotation Frequency }(\mathrm{RPM})
\end{aligned}
$$

\begin{tabular}{|c|c|c|c|c|c|c|}
\hline \multicolumn{3}{|c|}{ Input Gear } & \multicolumn{4}{|c|}{ Output Gear } \\
\hline $\begin{array}{c}\text { Speed } \\
(\mathrm{RPM})\end{array}$ & $\begin{array}{l}\text { Time } \\
(\mathrm{s})\end{array}$ & $\begin{array}{c}\text { Rotation } \\
\text { Freq. (Hz) }\end{array}$ & $\begin{array}{l}\text { Speed } \\
(\mathrm{RPM}) \\
\end{array}$ & $\begin{array}{c}\text { Time } \\
(\mathrm{s})\end{array}$ & $\begin{array}{c}\text { Rotation } \\
\text { Freq. }(\mathrm{Hz})\end{array}$ & $\begin{array}{l}\text { Gear Mesh } \\
\text { Freq. (Hz) }\end{array}$ \\
\hline 900 & 0.07 & 15 & 15 & 4.00 & 0.25 & 15 \\
\hline 1150 & 0.05 & 19.17 & 19.17 & 3.13 & 0.32 & 19.17 \\
\hline 1400 & 0.04 & 23.33 & 23.33 & 2.57 & 0.39 & 23.33 \\
\hline
\end{tabular}

Table 3. Input and output gear frequency

Vibration analysis. The vibration measurements were recorded by using accelerometer attached to a gearbox every three hours. Based on the previous analysis, the reading was performed at gear mesh frequencies of 15, 19 and $23 \mathrm{~Hz}$. Nevertheless, due to a low speed from the output shaft, it is difficult to distinguish as all fundamental frequencies are closely positioned in the spectrum (as shown in Fig. 3a). Aforementioned, there were three types of oil viscosity (VG100, VG460, VG680) were used as a baseline study. Initial result shown in Fig. $3 \mathrm{~b}$ indicates that the vibration amplitude of VG100 is higher than the other two type of lubricants, therefore displayed that a lower viscosity oil has higher vibration amplitude for each gear mesh frequencies.

Temperature analysis. The most important factor that affecting the quality of viscosity measurement is temperature. Therefore a slight variation in temperature can have a very large effect on the fluid viscosity. Based on previous research [3], that oil temperature of enclosed gear drives should never exceed $1093^{\circ} \mathrm{C}$ and the best service will be obtained at temperature in a range of $500-600{ }^{\circ} \mathrm{C}$. An increase of $10 \%$ or more in oil viscosity indicates that the lubricant has reached the end of its useful life. Fig. 4 shows the temperature versus running period of gearbox within 6 hours. The results showed that low viscosity lubricant contributes to low temperature stabilization. In this case, VG100 ended up at $34.93^{\circ} \mathrm{C}$ compare to VG680 which ended up at $39.5^{\circ} \mathrm{C}$ after 6 hours. Thus conclude that higher viscosity oil grade generates higher heat with less vibration observed. 

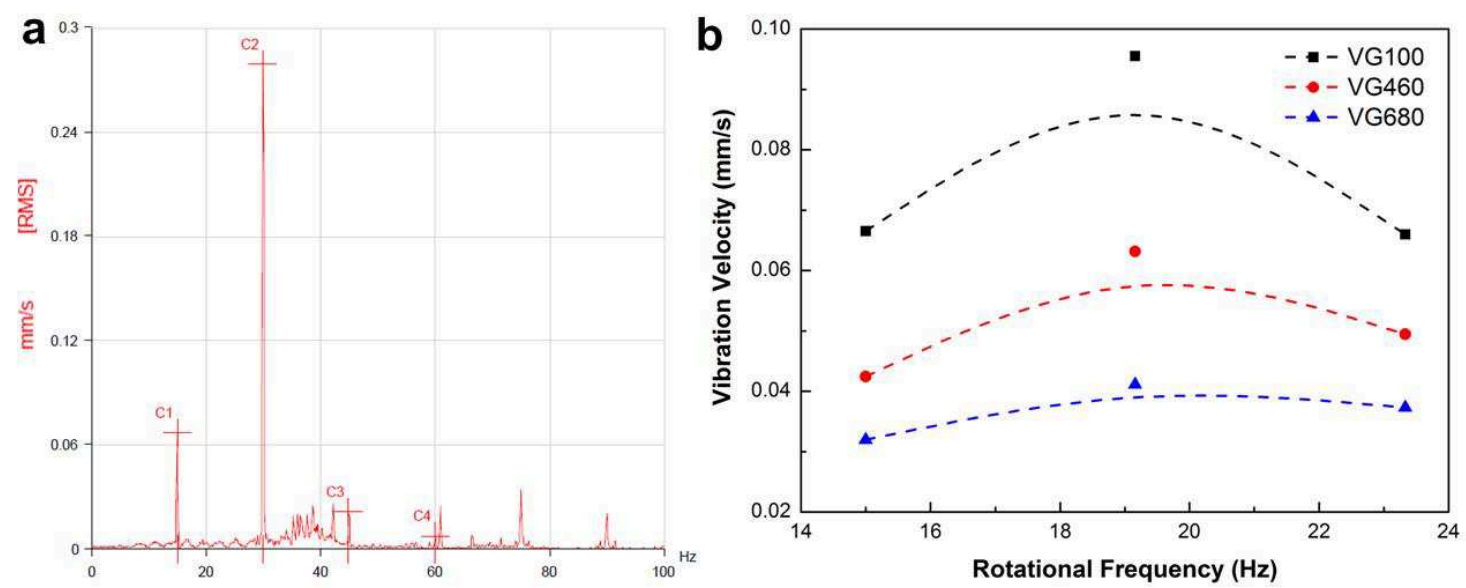

Fig. 3. (a) Dominant frequency for oil VG100 (b) Vibration amplitude at each rotation speed

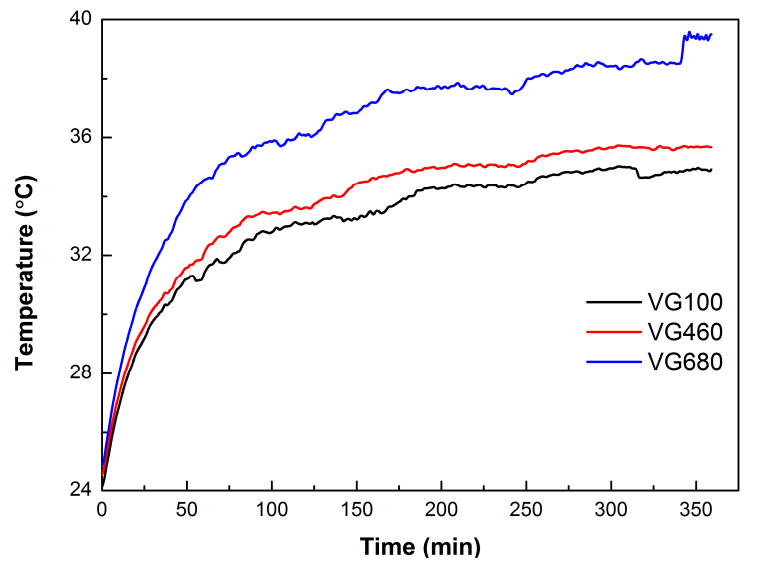

Fig. 4. Comparison of gear lubricant temperature

After the gearbox has finished running, the sample of gear oil was then removed and tested using Vibro Viscometer SV-10 to identify the changes in the viscosity. However, it can be seen that the viscosity does not change much as it observed less than 5\% as tabulated in Table 4.

Table 4. Gear lubricants viscosity

\begin{tabular}{lcc}
\hline \multirow{2}{*}{ Oil Grade } & \multicolumn{2}{c}{ Viscosity $(\mathrm{MPa} \cdot \mathrm{s})$} \\
\cline { 2 - 3 } & New oil & After 6 hours running \\
\hline VxG 100 & 223.9 & 235.0 \\
VG 460 & 434.5 & 455.1 \\
VG 680 & 894.6 & 921.4 \\
\hline
\end{tabular}

Worm Gear Surface. Figs. 5a and 5b show the new worm and wheel gear of the gearbox, respectively which both surface are smooth and no scratching marks. After six hours been running, the worm and wheel gear displayed minor scratches (as shown in Figs. 5c and 5d) which resulted from the worm gear's sliding contact with the wheel gear. A visual check on the gear surface finishing concludes that the gear has went through a machining process within a low quality control where a $1 \mathrm{~mm}$ diameter pin hole was found at the wheel throat as shown in Fig. $5 \mathrm{~d}$.

Thermograph. The thermograph images as shown in Fig. 6 display the radiation emitted from the gearbox surface. As the gearbox running at $900 \mathrm{RPM}$, the thermograph image reveals radiation at range of $31.2-31.9^{\circ} \mathrm{C}$ compare to the idle temperature at $25.4^{\circ} \mathrm{C}$. After six hours, the average radiation temperature increases to $35.5^{\circ} \mathrm{C}$. 


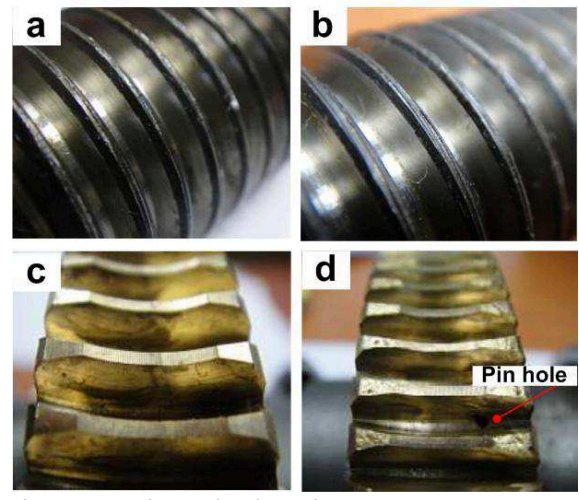

Fig. 5. Visual check on worm gear and wheel gear before and after used

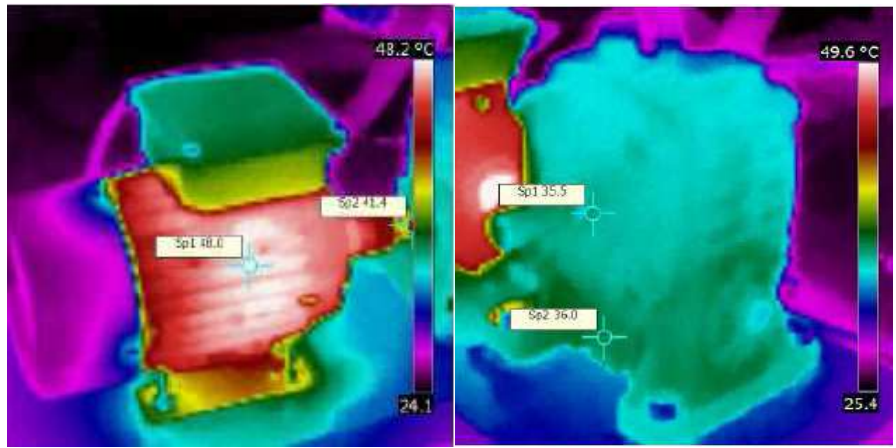

Fig. 6. Thermograph images of gearbox surface

\section{Conclusion}

Monitoring vibration and temperature of gearbox's internal component is one of the most important components of condition monitoring program. This research reveals more understanding on the dependent and independent roles of vibration and temperature in predicting and diagnosing the machine faults. The result concludes that a high viscosity lubricant contributes to lower vibration and higher temperature generation in the gearbox.

\section{Acknowledgement}

The authors thank the Universiti Tun Hussein Onn Malaysia for providing facilities and financial support for this research.

\section{References}

[1] M. Amarnath, C. Sujatha, S. Swarnamani, Experimental studies on the effect of reduction in gear tooth stiffness and lubricant film thickness in a spur geared system, Tribology International 42 (2009) 340-352.

[2] G. Bonori, F. Pellicano, Non-smooth dynamics of spur gears with manufacturing errors, Journal of Sound and Vibration 306 (2007) 271-283.

[3] M.D. Brouwer, L.A. Gupta, F. Sadeghi, D. Peroulis, D. Adams, High temperature dynamic viscosity sensor for engine oil applications, Sensors and Actuators, A: Physical 173 (2012) 102-107.

[4] B.C. Sharma, O.P. Gandhi, Performance evaluation and analysis of lubricating oil using parameter profile approach, Industrial Lubrication and Tribology 60 (2008) 131-137.

[5] I. Zaman, A. Khalid, B. Manshoor, S. Araby, M.I. Ghazali, The effects of bolted joints on dynamic response of structures, IOP Conference Series: Materials Science and Engineering 50 (2013) 012018.

[6] Z. Peng, N.J. Kessissoglou, M. Cox, A study of the effect of contaminant particles in lubricants using wear debris and vibration condition monitoring techniques, Wear 258 (2005) 1651-1662.

[7] M. Elforjani, D. Mba, A. Muhammad, A. Sire, Condition monitoring of worm gears, Applied Acoustics 73 (2012) 859-863.

[8] I. Zaman, B. Manshoor, A. Khalid, S. Araby, M.I. Ghazali, Vibration characteristics of composite plate embedded with shape memory alloy at elevated temperature, Applied Mechanics and Materials 393 (2013) 655-660.

[9] I. Zaman, M.M. Salleh, M. Ismon, B. Manshoor, A. Khalid, M.S.M. Sani, S. Araby, Vibration attenuation of plate using multiple vibration absorbers, MATEC Web of Conferences 13 (2014) 03003. 